Check for updates

Cite this: RSC Adv., 2020, 10, 9492

Received 29th November 2019 Accepted 18th February 2020

DOI: 10.1039/c9ra09997b

rsc.li/rsc-advances

\section{5-HMF production from glucose using ion exchange resin and alumina as a dual catalyst in a biphasic system}

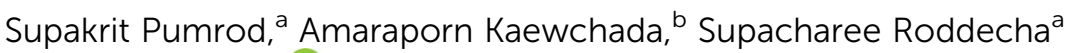 \\ and Attasak Jaree (iD *a
}

5-HMF is a platform chemical that can be used in many applications such as biofuels, monomers, industrial feed stocks, etc. In this work 5-HMF was synthesized from glucose in a biphasic system using a batch reactor. Aluminium oxide and ion exchange resin were used as catalysts in this system. The organic solvent and aqueous solvent were methyl isobutyl ketone (MIBK) and 1-methyl-2-pyrrolidinone (NMP). The effect of operating conditions for synthesis of 5-HMF on the yield and selectivity of 5-HMF was studied including aqueous-to-organic phase ratio, NMP-to-water ratio, catalyst dosage, ratio of catalyst, and reaction time. The optimal conditions were at the reaction temperature of $120{ }^{\circ} \mathrm{C}$ and reaction time of $480 \mathrm{~min}$, aqueous-to-organic phase ratio of $7: 3$, NMP-to-water ratio of $4: 1,0.3 \mathrm{~g}$ of catalyst, and the catalyst ratio of $1: 2$. The conversion of glucose, yield of $5-\mathrm{HMF}$, and selectivity of 5 -HMF were $94.036 \%, 84.92 \%$, and $90.48 \%$, respectively.

\section{Introduction}

5-Hydroxymethylfurfural is a versatile platform chemical that can be used to produce various building-block compounds such as furanic polyesters, polyamides, and polyurethanes due to the presence of both hydroxyl and aldehyde functional groups in the molecule. ${ }^{1,2}$ For example, 5-HMF can be oxidized over a metallic catalyst for the production of 2,5-furan dicarboxylic acid (FDCA), a chemical that can be used as raw material for the production of polyethylene furanoate (PEF). PEF offers similar physical, mechanical and chemical properties compared to polyethylene terephthalate (PET). Hence, it has a potential to partially substitute for terephthalic acid, which is used for the production of polyethylene terephthalate. 5-HMF can be hydrogenated to produce dihydroxymethyltetra hydrofuran (DHMTHF), a monomer for polymer synthesis, or other applications such as precursor for production of 1,6-hexanediol. Etherification of 5-HMF to 5-alkoxymethylfurfural ethers and hydrogenolysis of 5-HMF to dimethylfuran (DMF) have been proposed for liquid transportation fuels production. ${ }^{3-6}$ The main derivatives of 5-HMF are shown in Fig. 1.

Due to the great potential of 5-HMF production from carbohydrates such as cellulose, glucose and fructose, many studies on the development of 5-HMF synthesis using different

${ }^{a}$ Center of Excellence on Petrochemical and Materials Technology, Department of Chemical Engineering, Faculty of Engineering, Kasetsart University, Chatuchak, Bangkok, 10900, Thailand.E-mail: fengasj@ku.ac.th

${ }^{b}$ Department of Agro-Industrial, Food and Environmental Technology, King Mongkut's University of Technology North Bangkok, Bansue, Bangkok, 10800, Thailand catalysts have been reported. ${ }^{7-10}$ Avantium (chemical company) developed a large scale production of HMF and FDCA from carbohydrates through chemical catalysis. ${ }^{11}$ This work focused on the conversion of glucose to 5-HMF because it is the most abundant C6 sugar in nature. This process involves isomerization of glucose over base or Lewis acid sites followed by dehydration reaction over Brønsted acid catalysts as shown in Fig. 2. $^{12}$

In the 1990s, Kuster ${ }^{13}$ synthesized 5-HMF from fructose in a catalyst-free system by using water as a solvent and found that the conversion of fructose was quite low because 5-HMF can readily undergo rehydration with the surrounding water molecules producing levulinic acid and formic acid. In addition, polymerization of glucose, fructose, and 5-HMF can result in the

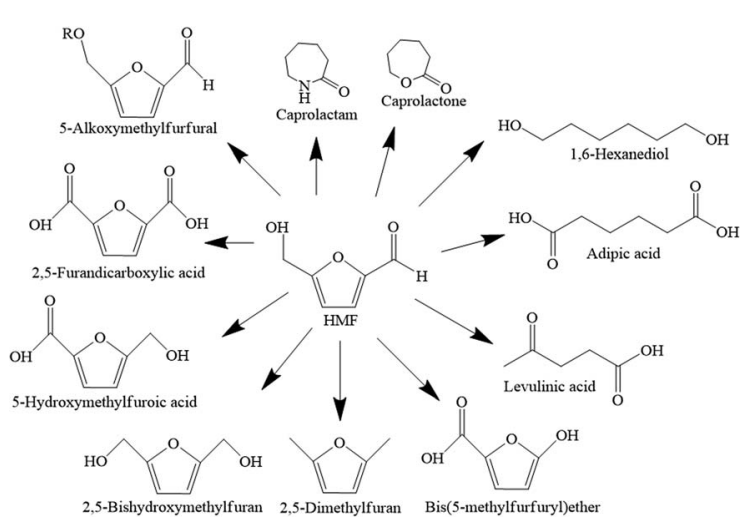

Fig. 1 Derivative of 5-HMF. 


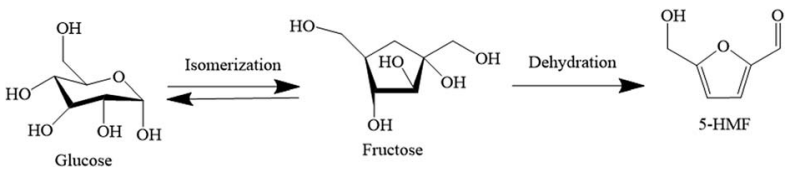

Fig. 2 Synthesis HMF from glucose.

formation of humins which is a by-product as shown in Fig. 3 . The synthesis of 5-HMF was also studied by using homogeneous acid catalyst such as hydrochloric acid $(\mathrm{HCl})$ and sulfuric acid $\left(\mathrm{H}_{2} \mathrm{SO}_{4}\right){ }^{14,15} \mathrm{Li}$ et al. obtained the yield of 5-HMF of $62.45 \%$ from the conversion of glucose using hydrochloric acid and sulfuric acid as catalyst at the reaction temperature of $140{ }^{\circ} \mathrm{C}$ and reaction time of 60 min. ${ }^{16}$ The Brønsted bases were used as catalyst but monosaccharides were unstable under such conditions leading to the formation of by-products. However, there are some drawbacks associated with the application of homogeneous catalyst including the separation of product and solvent, by-product formation, and corrosion of equipment. These issues lead to the increased production cost. To alleviate these problems, the use of heterogeneous catalyst with high polarity solvent such as dimethyl sulfoxide or DMSO, tetrahydrofuran or $\mathrm{THF}^{17,18}$ and 1-ethyl-3-methylimidazolium chloride, $[\mathrm{BMM}][\mathrm{Cl}]$ was proposed. ${ }^{19}$ Degirmenci et al. studied glucose dehydration into 5-HMF using Lewis acidic metal chlorides $\left(\mathrm{MeCl}_{x}\right) /$ ionic liquid/SBA-15 as catalyst and obtained the glucose conversion of $46 \%$ and the yield of 5-HMF of $22 \%$ at $150{ }^{\circ} \mathrm{C}$ with the reaction time of $3 \mathrm{~h}^{.20}$ However, the product-solvent separation is necessary to recycle the solvent as well as to obtain high purity product. Besides, the yield of 5-HMF was relatively low compared to that of the homogeneous catalyst system. As an alternative to the use of ionic liquid, Musau et al. studied the synthesis of 5-HMF using cation-exchange resin (Diaion PK216) and dimethylsulfoxide as solvent. ${ }^{21}$ The conversion of glucose of approximately $90 \%$ was obtained at the reaction temperature of $90{ }^{\circ} \mathrm{C}$ and the reaction time of $600 \mathrm{~min}$. $\mathrm{N}$-Methyl-2-pyrrolidone (NMP) was also successfully applied as solvent for the synthesis of 5-HMF from glucose in a biphasic system using cationexchange resin as catalyst. ${ }^{22}$ The conversion of glucose of $90 \%$ and 5 -HMF yield of $83 \%$ were achieved at the reaction temperature of $90{ }^{\circ} \mathrm{C}$ and reaction time of $12 \mathrm{~h}$.

In this study, 5-HMF was produced by using dual heterogeneous catalyst in a biphasic system. High porosity cation-exchange resin with sulfonic group and aluminium oxide $\left(\mathrm{Al}_{2} \mathrm{O}_{3}\right)$ was used as Brønsted acid and Lewis acid, respectively. The effect of reaction time, $\mathrm{N}$-methyl-2-pyrrolidone-water ratio in aqueous phase, aqueous-organic phase ratio, the amount of catalyst, ratio of catalysts (cation-exchange resin and aluminium oxide) on the conversion of glucose as well as yield and selectivity of 5-HMF was investigated. $\mathrm{NaCl}$ was added to increase immiscibility between aqueous and organic phase, and finally layered as two phases. The HMF product which in situ occurred in aqueous phase was extracted to the organic phase and the side reaction was terminated. Results were also compared with the literature data in terms of reaction conditions, yield of 5-HMF, and selectivity of 5HMF.

\section{Material \& methods}

\subsection{Material}

All chemicals including 1-methyl-2-pyrrolidinone (NMP), acetonitrile (HPLC grade), and 5-hydroxymethylfurfural (AR grade) for HPLC calibration were purchased from SigmaAldrich. Methyl isobutyl ketone (AR grade) was purchased from Merck. D-Glucose (AR grade) was purchased from Fisher Scientific. Aluminium oxide was purchased from APS. Ionexchange resin (DIAION® RCP160M) catalyst was supplied by Mitsubishi Chemical Corporation.

\subsection{Catalyst characterization}

In this work, dual catalyst was used to synthesize 5-HMF from glucose in a biphasic system. Two types of acid catalyst in the form of cation exchange resin with sulfonic, $-\mathrm{HSO}_{3}$ functional groups and aluminium oxide $\left(\mathrm{Al}_{2} \mathrm{O}_{3}\right)$ were used for the conversion of glucose to 5-HMF. The total number of acid sites on the ion-exchange resin and aluminium oxide surfaces was determined by acid-base back neutralization titration method and $\mathrm{NH}_{3}$-TPD, respectively. The catalysts were suspended in $0.1 \mathrm{M}$ sodium hydroxide aqueous solution and stirred for $4 \mathrm{~h}$ followed by ultrasonication for $1 \mathrm{~h}$ at room temperature. The concentration of $\mathrm{OH}^{-}$ions in the mixture was calibrated by a standard solution of $0.1 \mathrm{M}$ hydrochloric acid. Phenolphthalein was used as an indicator for this titration. The titration continued until the mixture was neutralized. The catalyst was also characterized by Xray diffraction (XRD), Fourier Transform Infrared Spectrophotometer (FTIR) and $\mathrm{N}_{2}$ adsorption-desorption.

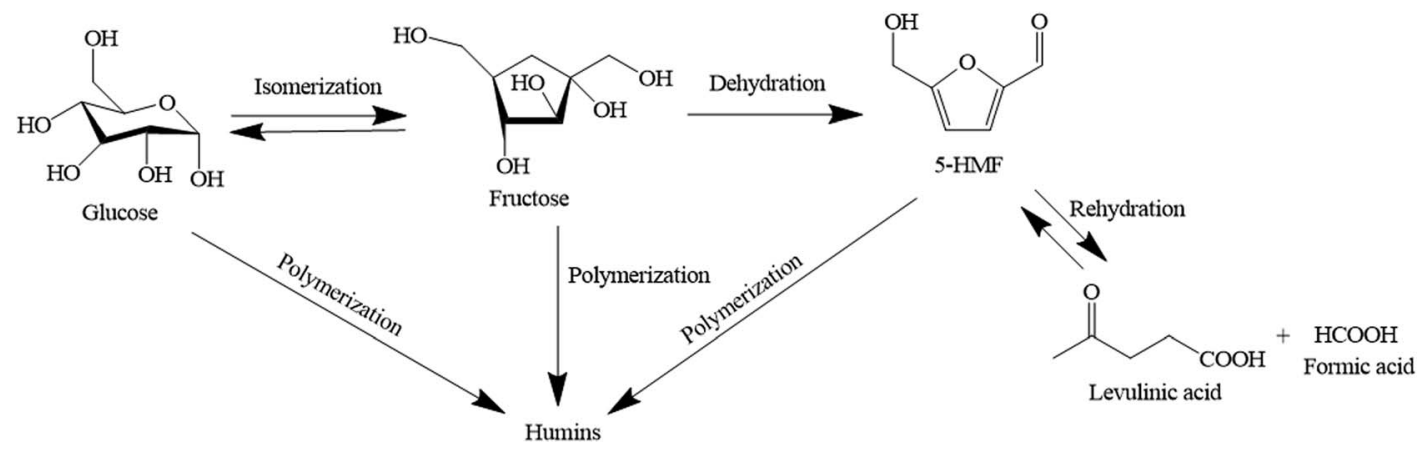

Fig. 3 Reaction scheme for 5-HMF production from glucose. 


\subsection{Synthesis of 5-HMF from glucose}

The synthesis of 5-HMF was performed in a closed system. The reactor was a round-bottom glass reactor equipped with a reflux condenser. For a typical experiment, glucose, aluminium oxide, cation-exchange resin, $\mathrm{NaCl}, \mathrm{N}$-methyl-2-pyrrolidone, water and MIBK were loaded in the reactor at ambient temperature. The glass reactor was then placed in an oil bath with internal circulation for temperature control at $120^{\circ} \mathrm{C}$. During experiment, the reacting mixture and catalyst were continuously stirred. After a certain period of reaction time has elapsed, the reaction was quenched by placing the glass reactor in an ice bath at $0{ }^{\circ} \mathrm{C}$ immediately. The solution was filtered by vacuum filtration. The organic layer and aqueous layer were separated and analyzed by high performance liquid chromatography (HPLC).

\subsection{Product analysis}

The liquid samples collected from batch experiments were analyzed by high performance liquid chromatography (HPLC). The Sugar HMP column $(3.5 \mu \mathrm{m}, 4.6 \times 100 \mathrm{~mm})$ was used to determine the amount of glucose by using RI detector (model YL9170, YL Instrument). The column temperature was maintained by a column oven (model TCM-004076, Waters) at $60{ }^{\circ} \mathrm{C}$, and mobile phase was $0.005 \mathrm{M}$ sulfuric acid solution at a flow rate of $0.4 \mathrm{ml} \mathrm{min}{ }^{-1}$. The amount of 5-HMF in both layers was determined using UV detector (model 2550, Varian) at the wavelength of $320 \mathrm{~nm}$. The ACE Excel 5 Super C18 reverse phase column $(4.6 \mathrm{~mm} \times 250 \mathrm{~mm}, 5 \mu \mathrm{m}$ particle size, Advanced Chromatography Technologies) was held at $30{ }^{\circ} \mathrm{C}$ and the mobile phase was acetonitrile : water $(10: 90(\mathrm{v} / \mathrm{v}))$ at the flow

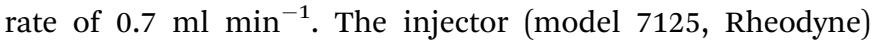
volume of the sample (filtered through $0.45 \mu \mathrm{m}$ Nylon syringe filter membrane) was $20 \mu \mathrm{L}$. The analysis was repeated three times. The conversion of glucose, the yield of 5-HMF, and the selectivity of 5-HMF were calculated as follows:

\section{Conversion of glucose}

Conv. $(\%)=(1-($ moles of glucose unreacted $/$ moles of starting glucose units) $) \times 100 \%$

Yield of 5-HMF

$$
\begin{aligned}
\text { YHMF }(\%)= & (\text { moles of HMF produced } / \text { moles of } \\
& \text { starting glucose units }) \times 100 \%
\end{aligned}
$$

Selectivity of 5 -HMF

$$
\text { SHMF }(\%)=(\text { YHMF/Conv. }) \times 100 \%
$$

\section{Result and discussion}

\subsection{The characterization of catalyst}

First, the composition of aluminium oxide was determined by using XRD technique (Bruker D8 Advance). As shown in Fig. 4, the peaks were found at $2 \theta$ of $25.6^{\circ}, 32.9^{\circ}, 35.2^{\circ}, 37.7^{\circ}, 43.4^{\circ}$, $45.5^{\circ}, 52.6^{\circ}, 57.5^{\circ}$, and $67.2^{\circ}$, respectively. The peaks which located at $25.6^{\circ}, 35.2^{\circ}, 43.4^{\circ}, 52.6^{\circ}$ and $57.5^{\circ}$ indicated that traces of $\alpha$-alumina was present in the catalyst. The percentages of alpha-alumina and gamma-alumina were $34.9 \%$ and $65.1 \%$, respectively.

To investigate the functional groups which involve the exchanging ion of cation-exchange resin, FTIR (PERKIN ELMER Spectrum One) was used. The FTIR spectrum is presented in Fig. 5. The peak located at $3500 \mathrm{~cm}^{-1}$ contributed to the $\mathrm{O}-\mathrm{H}$ stretching and the $\mathrm{C}=\mathrm{C}$ stretching was indicated at $1700 \mathrm{~cm}^{-1}$. In addition, the peaks at 1200 and $1000 \mathrm{~cm}^{-1}$ were associated with the $\mathrm{S}=\mathrm{O}$ stretching. Therefore, sulfonic functional groups were present on the cation-exchange resin.

The surface area of catalyst was studied by $\mathrm{N}_{2}$-sorption technique. As summarized in Table 1 , it was found that the surface areas of aluminium oxide and cation-exchange resin were 74.8 and $48.5 \mathrm{~m}^{2} \mathrm{~g}^{-1}$, respectively. This surface area was similar to that of the Amberlyst-15 used for the synthesis of hydroxymethylfurfural by Tuteja et al., who reported the conversion of glucose and the yield of hydroxymethylfurfural at the optimal conditions of $82 \%$ and $37 \%$, respectively. ${ }^{23}$ The acidity of catalyst was measured by titration and $\mathrm{NH}_{3}$-TPD method. It was found that the acidity of cation-exchange resin and aluminium oxide were 6.77 and $0.91 \mathrm{mmol} \mathrm{g}^{-1}$, respectively.

\subsection{Effect of aqueous : organic phase ratio}

In a biphasic system, MIBK has been applied to prevent undesired reactions of 5-HMF in the aqueous phase. Compared to butanol and THF, MIBK offers better partitioning effect by transferring 5-HMF into the organic phase. ${ }^{28}$ Therefore, the $\mathrm{NMP} / \mathrm{H}_{2} \mathrm{O}$ and MIBK were used in this study. The $\mathrm{NMP} / \mathrm{H}_{2} \mathrm{O}$ and MIBK volume ratio was varied from $5: 5$ to $2: 8$ and the total volume of mixture was constant at $10 \mathrm{ml}$. The amount of catalyst and catalyst ratio was constant at $0.4 \mathrm{~g}$ and $1: 1$, respectively. The reaction time, temperature and $\mathrm{NMP} / \mathrm{H}_{2} \mathrm{O}$ ratio were held constant at $360 \mathrm{~min}, 120^{\circ} \mathrm{C}$ and $3: 1$, respectively. Fig. 6 shows the effect of aqueous and organic phase ratio on the yield of 5HMF, conversion of glucose, and selectivity toward 5-HMF. It

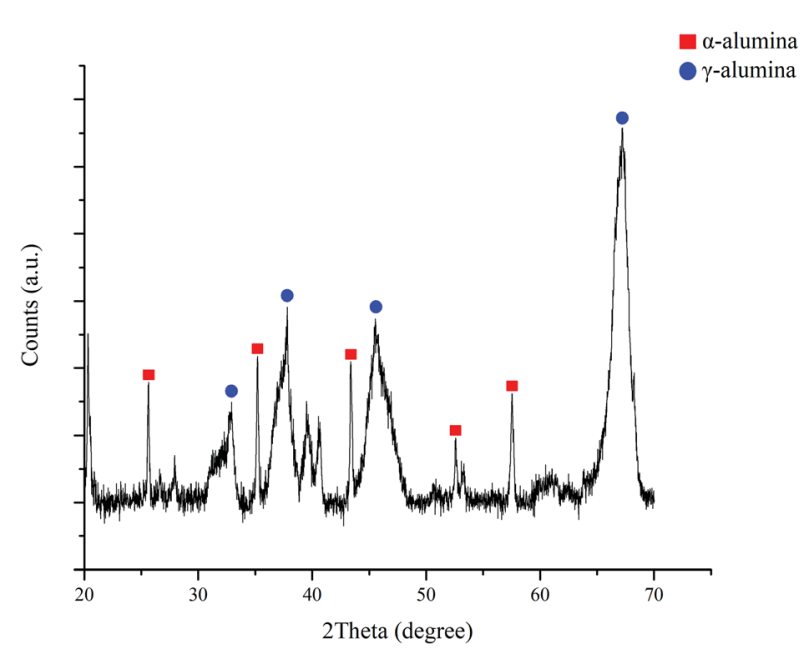

Fig. 4 XRD pattern of aluminium oxide. 


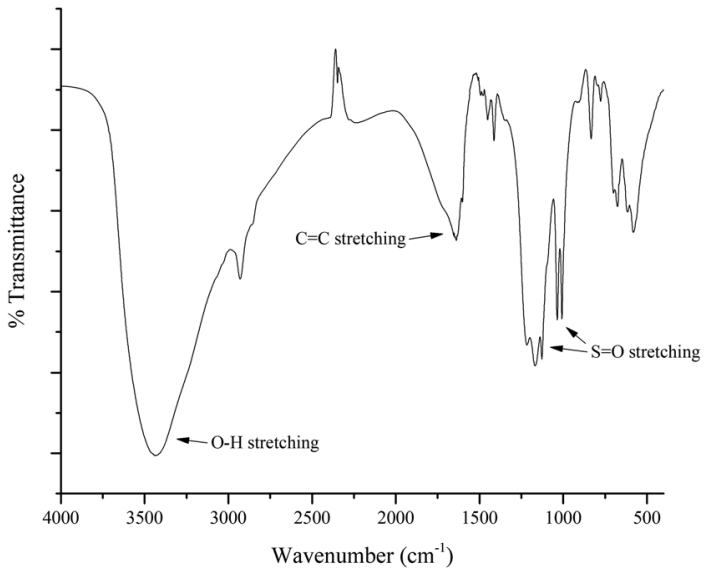

Fig. 5 FTIR spectrum of cation exchange resin.

Table 1 Surface areas of catalyst

\begin{tabular}{lll}
\hline Catalyst & $S_{\text {BET }}\left(\mathrm{m}^{2} \mathrm{~g}^{-1}\right)$ & Source \\
\hline Aluminium oxide & 74.8 & This work \\
Cation exchange resin & 48.5 & This work \\
Amberlyst-15 & 50 & 24 \\
Zirconium dioxide & 17 & 25 \\
Titanium dioxide & 100 & 25 \\
$\mathrm{Fe}_{3} \mathrm{O}_{4} @ \mathrm{SiO}_{2}-\mathrm{SO}_{3} \mathrm{H}$ & 106.8 & 26 \\
$\mathrm{SiO}_{2}-\mathrm{ATS}-\mathrm{PTA}$ & 290.55 & 27
\end{tabular}

was found that at aqueous and organic phase ratio between $5: 5$ and $3: 7$ decreasing the volume ratio of aqueous phase to organic phase boosted the conversion of glucose and the yield of 5-HMF. This was due to the transfer of 5-HMF from aqueous phase to organic phase, preventing the undesired reaction (rehydration) of 5-HMF in the aqueous phase. The excess amount of water in the system can lead to the formation of levulinic acid and formic acid. However, lowering the aqueousto-organic phase ratio from $3: 7$ to $2: 8$ decreased the 5 -HMF yield and selectivity from $33.61 \%$ to $39.38 \%$ and $15.96 \%$ to $18.2 \%$, respectively. It was probable that the part of the aqueous phase dissolved into the excess MIBK and vice versa. Hence, in the aqueous phase, the concentration of NMP (phase modifier) was affected as well as the glucose concentration, promoting the conversion of glucose to other by-products. A similar effect was reported for the study of the conversion of glucose into 5-HMF using different solvents and catalysts. ${ }^{29}$ Kuster et al. ${ }^{13}$ reported that cross-polymerization during the dehydration of fructose to produce 5-HMF resulted in the formation of humins, especifically in aqueous systems.

\subsection{Effect of $\mathrm{NMP} / \mathrm{H}_{2} \mathrm{O}$ ratio}

To improve the reaction performance for the synthesis of 5$\mathrm{HMF}$, the effect of $\mathrm{NMP} / \mathrm{H}_{2} \mathrm{O}$ volume ratio was investigated. The $\mathrm{NMP} / \mathrm{H}_{2} \mathrm{O}$ volume ratio was varied from $1: 1$ to $4: 1$ while the reaction time and temperature were held as constant at $360 \mathrm{~min}$ and $120{ }^{\circ} \mathrm{C}$, respectively. The volumes of aqueous and organic

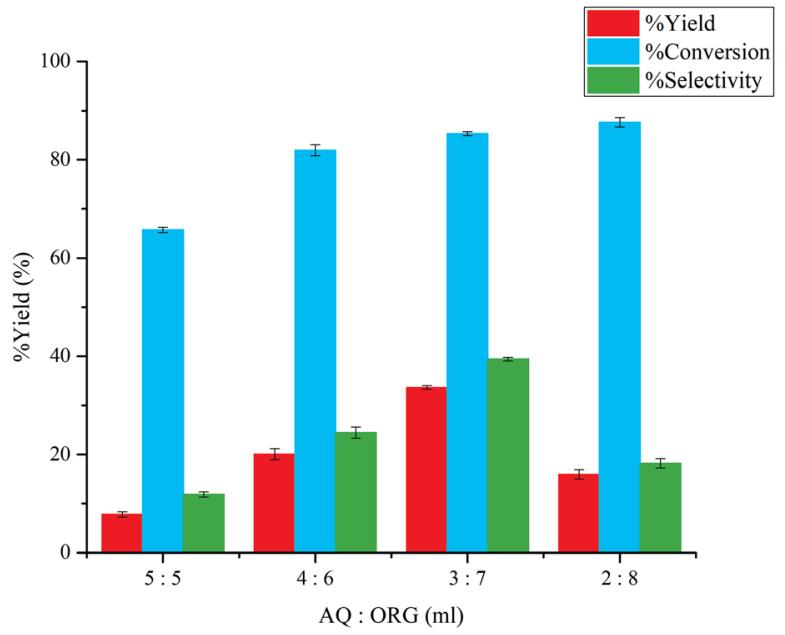

Fig. 6 Effect of aqueous : organic phase ratio. Reaction conditions: $0.1 \mathrm{~g}$ of glucose, $0.2 \mathrm{~g}$ of cation exchange resin, $0.2 \mathrm{~g}$ of aluminium oxide, $0.4 \mathrm{~g}$ of sodium chloride, NMP : $\mathrm{H}_{2} \mathrm{O} 3: 1,120^{\circ} \mathrm{C}$ and $360 \mathrm{~min}$.

phase were 3 and $7 \mathrm{ml}$. As shown in Fig. 7, it was found that increasing the $\mathrm{NMP} / \mathrm{H}_{2} \mathrm{O}$ volume ratio from $1: 1$ to $2: 1$ resulted in a marked increase in the glucose conversion, yield of 5-HMF, and selectivity of 5-HMF. This was due to the tautomerism of fructose in NMP that favors the formation of fructofuranose. This form of fructose is relatively active towards the formation of 5-HMF compared to other forms ${ }^{28}$ Therefore, the isomerization of glucose was shifted to the product formation. Further increasing the $\mathrm{NMP} / \mathrm{H}_{2} \mathrm{O}$ volume ratio to $4: 1$ resulted in almost a linear increase for both 5 -HMF yield and selectivity while the glucose conversion appeared to level off around $85 \%$. This was because NMP acted as an aqueous phase modifier preventing the formation of humin in water. Similar results were also reported by Chheda et al. who studied the conversion of fructose to 5-HMF by ion exchange resin as catalyst in biphasic system. This reduced the possibility of 5-HMF undergoing rehydration to form other by-products. ${ }^{17}$ Horvat $e t$ al. explained that the addition of water to the 2, 3-carbon positions on 5-HMF resulted in the undesired reactions (polymerization reactions) which can form humin. ${ }^{30}$ Furthermore, the addition of water to 4, 5-carbon positions led to the formation of levulinic acid and formic acid. Therefore, the beneficial effect of NMP on 5-HMF formation is related to its ability to minimize ring opening of these carbon atoms. In this system, there were four different tautomeric forms of D-fructose (two pyranoids and two furanoids). The furanoid form is promoted in DMSO and NMP due to the similar molecular structure. The dehydration of fructose in this from can undergo dehydration to selectively produce 5-HMF. However, further increasing of $\mathrm{NMP} / \mathrm{H}_{2} \mathrm{O}$ ratio from $4: 1$ to $1: 0$ resulted in a negative effect on the glucose conversion, yield and selectivity of 5 -HMF from $83.85 \%$ to $72.84 \%, 53.99 \%$ to $36.58 \%$ and $66.77 \%$ to $37.16 \%$, respectively. This was due to the transfer of NMP into the organic phase and also the hydrophilic nature of the sulfonic group of the cation exchange resin. Consequently, the activity of RCP160M was reduced substantially. This was in line with the work by Chen et al., who studied the 


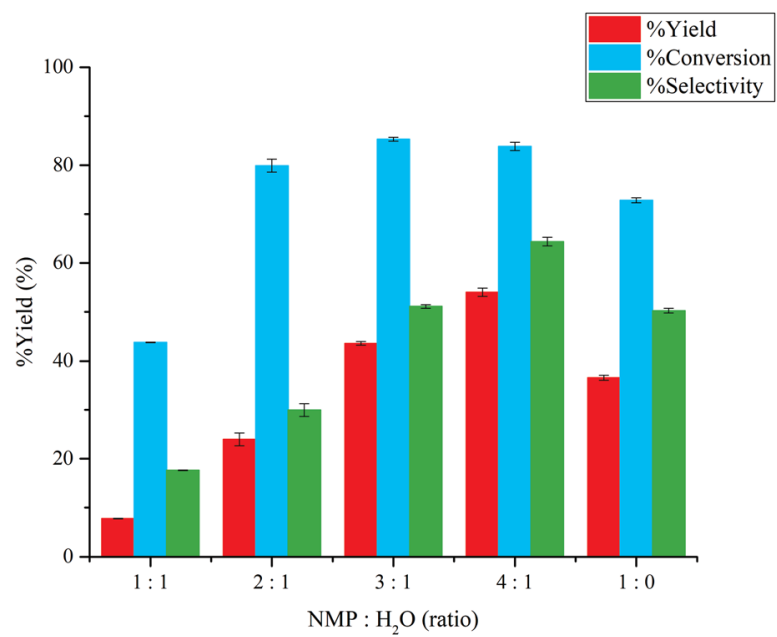

Fig. 7 Effect of NMP : $\mathrm{H}_{2} \mathrm{O}$ volume ratio. Reaction conditions: $0.1 \mathrm{~g}$ of glucose, $0.2 \mathrm{~g}$ of cation exchange resin, $0.2 \mathrm{~g}$ of aluminium oxide, $0.4 \mathrm{~g}$ of sodium chloride, aqueous : organic phase volume $3: 7,120^{\circ} \mathrm{C}$ and $360 \mathrm{~min}$.

conversion of glucose to 5 -HMF by using porous coordination polymer as heterogeneous catalysts. ${ }^{31}$

\subsection{Effect of catalyst amount}

The influence of catalyst dosage on the activity was investigated by varying the total amount of catalyst in the range of $0.10-$ $0.40 \mathrm{~g}$. Other parameters were kept constant. All experiments were carried out with the ratio between cation exchange resin and $\mathrm{Al}_{2} \mathrm{O}_{3}$ of $1: 1$, NMP : MIBK ratio of $3: 7,0.4 \mathrm{~g} \mathrm{NaCl}$, and $0.1 \mathrm{~g}$ glucose at $120^{\circ} \mathrm{C}$ for $360 \mathrm{~min}$. As shown in Fig. 8, the yield of 5 -HMF increased from $24.68 \%$ to $64.86 \%$ with increasing the amount of catalyst up to $0.30 \mathrm{~g}$. Further increasing the amount of catalyst resulted in a slight decrease for both yield and selectivity of 5-HMF. It was possible that excess active site provided by the high catalyst loading simultaneously induced side reactions to some degree. Thus, the optimal catalyst amount in this system was $0.30 \mathrm{~g}$. Similar results were reported by Elsayed et al. for the dehydration of glucose to 5-HMF using core-shell $\mathrm{Fe}_{3} \mathrm{O}_{4} @ \mathrm{SiO}_{2}-\mathrm{SO}_{3} \mathrm{H}$ magnetic nanoparticles. ${ }^{32}$

\subsection{Effect of catalyst ratio}

The effect of catalyst ratio was evaluated with the constant reaction time of $360 \mathrm{~min}$ and the reaction temperature of $120{ }^{\circ} \mathrm{C}$. The catalyst ratio was studied from $1: 0$ to $0: 1$ while the total amount of catalyst was kept constant at $0.30 \mathrm{~g}$. As shown in Fig. 9, a dramatic increase in terms of glucose conversion, 5-HMF yield, and 5-HMF selectivity was observed when the catalyst ratio was changed from $1: 0$ to $1: 1$. This was due to the fact that ion-exchange resin (Brønsted acid) was not effective for isomerization reaction. The presence of aluminium oxide (Lewis acid) allowed the isomerization of glucose to proceed more efficiently. This reaction was also enhanced by the dehydration of fructose and the transfer of 5HMF into the organic phase. Lowering the catalyst ratio from

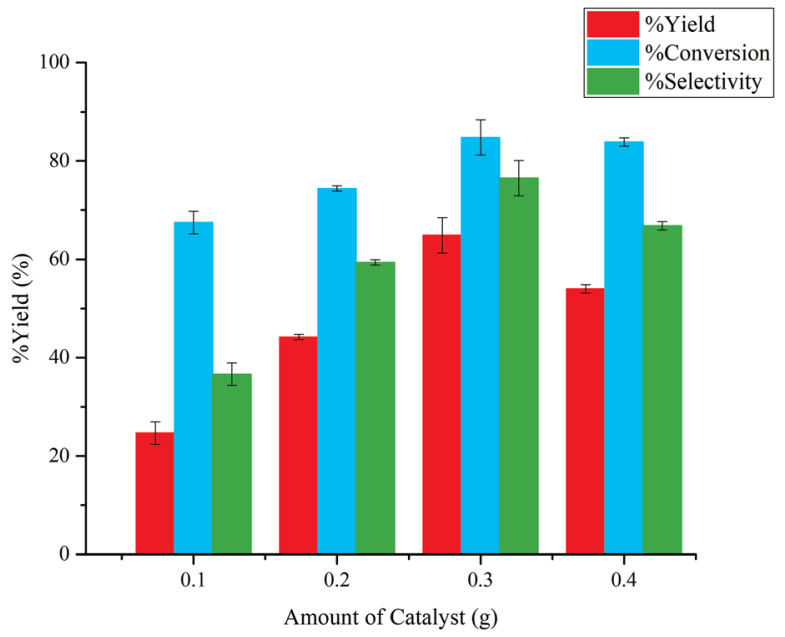

Fig. 8 Effects of catalyst amount. Reaction conditions: $0.1 \mathrm{~g}$ of glucose, $0.4 \mathrm{~g}$ of sodium chloride, aqueous : organic phase volume $3: 7, \mathrm{NMP}: \mathrm{H}_{2} \mathrm{O} 4: 1,120{ }^{\circ} \mathrm{C}$ and $360 \mathrm{~min}$.

$1: 1$ to $1: 2$ resulted in a slight increase of glucose conversion and the yield of 5 -HMF to $94.04 \%$ and $71.23 \%$, respectively, while the selectivity of 5-HMF was approximately the same. With two-thirds of catalyst being aluminium oxide, the isomerization proceeded rapidly. Despite the fact that the amount of cation-exchange resin was decreased from 0.15 to $0.10 \mathrm{~g}$ at this ratio, the effect of equilibrium shifting prevailed. Further decreasing the catalyst ratio to $1: 3$ resulted in a marked decline in the yield and selectivity of 5-HMF while the conversion of glucose increased slightly. Conceivably, the increased amount of alumina at this ratio enhanced the formation of humin from glucose. For the catalyst ratio of $0: 1$, we observed a substantial decline in the glucose conversion, yield of 5-HMF, and selectivity of 5-HMF. This was due to lack of Brønsted acid sites necessary for the dehydration of fructose. Hence, both glucose and fructose were

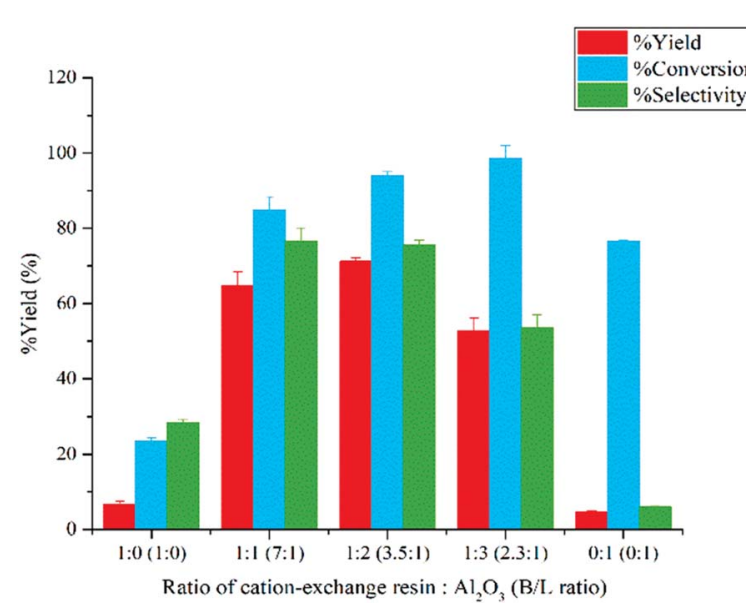

Fig. 9 Effect of catalyst ratio and Brønsted: Lewis acid sites ratio. Reaction conditions: $0.1 \mathrm{~g}$ of glucose, $0.4 \mathrm{~g}$ of sodium chloride, aqueous: organic phase volume $3: 7, \mathrm{NMP}: \mathrm{H}_{2} \mathrm{O} 4: 1,120{ }^{\circ} \mathrm{C}$ and $360 \mathrm{~min}$ 


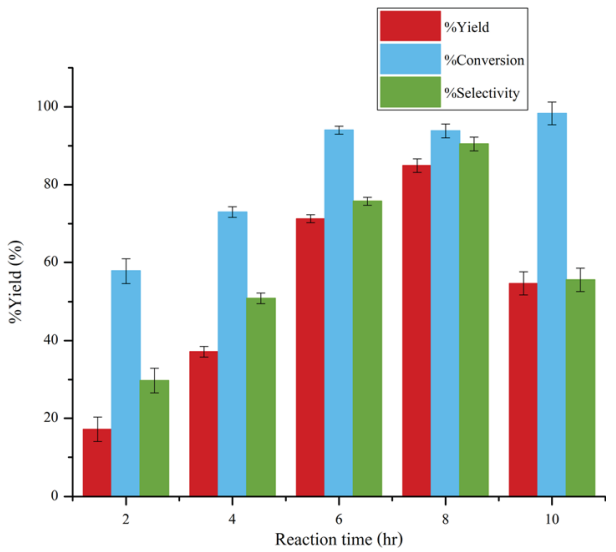

Fig. 10 Effects of reaction time. Reaction conditions: $0.1 \mathrm{~g}$ of glucose, $0.4 \mathrm{~g}$ of sodium chloride, catalyst ratio of $1: 2$, aqueous : organic phase volume ratio of $3: 7, \mathrm{NMP}: \mathrm{H}_{2} \mathrm{O}$ of $4: 1$, reaction temperature of $120{ }^{\circ} \mathrm{C}$.

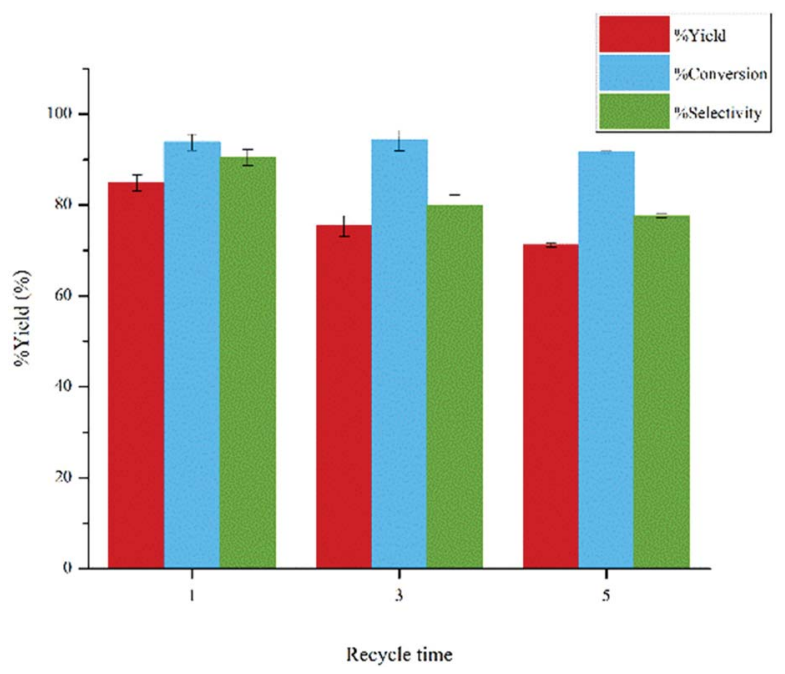

Fig. 11 Effect of catalyst reuse.

polymerized to form other by-products. A similar behavior was reported by Núñez et al., who used $\gamma-\mathrm{Al}_{2} \mathrm{O}_{3}$ as acid catalyst for the dehydration of glucose to 5-HMF. Therefore, the optimal catalyst ratio of $1: 2$ will be used for all subsequent experiments.

\subsection{Effect of reaction time}

A set of experiments were performed at $120{ }^{\circ} \mathrm{C}$ with the aqueous : organic phase volume ratio of $3: 7, \mathrm{NMP} / \mathrm{H}_{2} \mathrm{O} 4: 1,0.1 \mathrm{~g}$ of ion exchange resin and $0.2 \mathrm{~g}$ of aluminium oxide while the reaction time was varied from 120-600 min. As shown in Fig. 10, the conversion of glucose, 5-HMF yield, and 5-HMF selectivity increased almost linearly with increasing reaction time from $120 \mathrm{~min}$ to $360 \mathrm{~min}$. Further increasing the reaction time to 480 min resulted in a slight increase of 5-HMF yield and selectivity while the conversion of glucose was approximately constant. This might be caused by the slow transfer of 5-HMF from aqueous phase into the organic phase. However, at the reaction time of $600 \mathrm{~min}$, the yield and selectivity of 5-HMF dropped to $54.65 \%$ and $55.57 \%$, respectively. This can be explained that a great extent of 5-HMF was further converted to by-products due to the prolonged reaction time..$^{33}$ Therefore, the optimal conditions were as follows: $0.1 \mathrm{~g}$ of glucose, $0.4 \mathrm{~g}$ of sodium chloride, catalyst ratio of $1: 2$, aqueous : organic phase volume ratio of $3: 7, \mathrm{NMP}: \mathrm{H}_{2} \mathrm{O}$ of $4: 1$, reaction temperature of $120{ }^{\circ} \mathrm{C}$, and reaction time of $480 \mathrm{~min}$. The glucose conversion, 5-HMF yield, and 5-HMF selectivity were $93.85 \%$, 84.92\%, and $90.48 \%$, respectively.

\subsection{Reuse of catalyst}

To examine the stability of our catalyst, the system was scaled up with the aqueous : organic phase of $6: 14, \mathrm{NMP} / \mathrm{H}_{2} \mathrm{O} 4: 1$, 0.8 sodium chloride, ion exchange resin $0.2 \mathrm{~g}$ and aluminium oxide $0.4 \mathrm{~g}$. The experiments were carried out at the reaction temperature and reaction time of $120{ }^{\circ} \mathrm{C}$ and $360 \mathrm{~min}$, respectively. The yields of the 5 -HMF reduced from $84.92 \%$ to $71.15 \%$ after five consecutive runs as shown in Fig. 11 . The total acidity of ion exchange resin decreased to $5.48 \mathrm{mmol} \mathrm{g}^{-1}$ after 3 runs and finally decreased to $4.06 \mathrm{mmol} \mathrm{g}^{-1}$ after 5 runs. The change of catalytic activity was presumably attributed to the adsorption and accumulation of oligomeric products on the acid sites of catalyst.

\subsection{Comparison of catalyst performance}

The performance of catalyst for 5-HMF production from glucose was evaluated at the optimal operating conditions and compared with the literature data. The comparison was summarized in Table 2. It was found that synthesis 5-HMF from glucose in a monophasic system using homogeneous catalyst

Table 2 Catalyst performance for 5-HMF synthesis from glucose

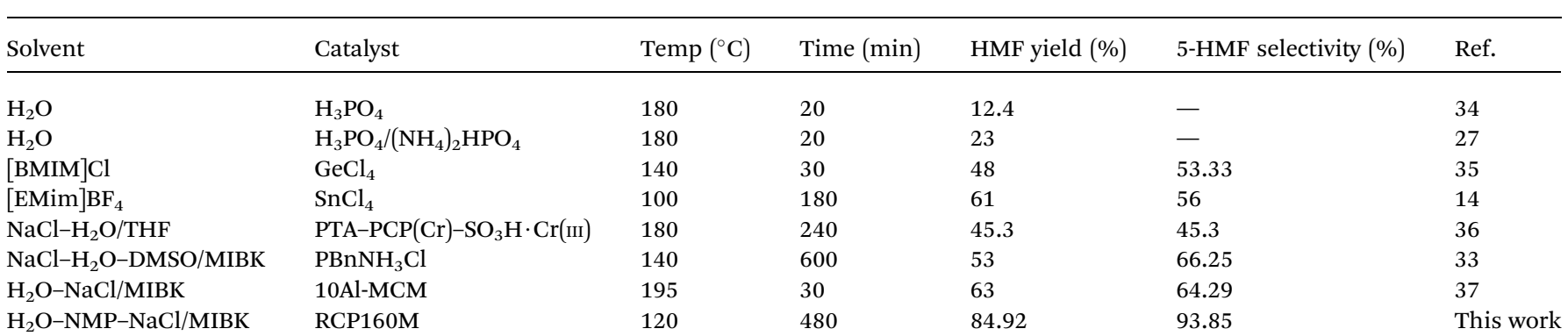


provided relatively low selectivity and yield of 5-HMF. The use of ionic liquid and heterogeneous catalyst was able to enhance the synthesis of 5-HMF. However, this system requires a separation process to purify the product as well as to recycle the catalyst. Relatively high yield of 5-HMF was obtained in a biphasic system. Among these, our system offered much lower temperature and shorter reaction time while the yield and selectivity of 5-HMF was significantly higher than that of other systems.

\section{Conclusions}

In this study, the potential of dual catalyst as a mixture of ion exchange and aluminium oxide for the synthesis 5-HMF from glucose in a biphasic system was successfully demonstrated. The NMP-to-water ratio enhanced the conversion of glucose, yield and selectivity of 5-HMF. However, pure NMP as the aqueous solvent turned the system into single phase. Increasing the amount of catalyst promoted the synthesis of 5-HMF. Excess catalyst also facilitated undesired side reactions. The ratio of Lewis acid and Brønsted acid of $2: 1$ was suitable for a series of isomerization and dehydration. The reaction time of $8 \mathrm{~h}$ was sufficient to obtain high yield of 5-HMF without a significant loss through other side reactions. The glucose conversion, yield and selectivity of $5-\mathrm{HMF}$ of $84.92 \%, 90.48 \%$, and $93.85 \%$, respectively, were obtained at the optimal conditions.

\section{Conflicts of interest}

There are no conflicts to declare.

\section{Acknowledgements}

The authors would like to thank Mitsubishi Chemical Corporation for providing the Ion-exchange resin (DIAION ${ }^{\circledR}$ RCP160M) catalyst for this study. The financial support from the Agricultural Research Development Agency (Public Organization), grant number CRP6205031540, is acknowledged.

\section{References}

1 Y. Yang, Q. Liu, D. Li, J. Tan, Q. Zhang, C. Wang and L. Ma, RSC Adv., 2017, 7, 16311-16318.

2 T. Wang, M. W. Nolte and B. H. Shanks, Green Chem., 2014, 16, 548-572.

3 R.-J. van Putten, J. C. van der Waal, E. de Jong, C. B. Rasrendra, H. J. Heeres and J. G. de Vries, Chem. Rev., 2013, 113, 1499-1597.

4 D. M. Alonso, J. Q. Bond and J. A. Dumesic, Green Chem., 2010, 12, 1493-1513.

5 F. H. Isikgor and C. R. Becer, Polym. Chem., 2015, 6, 44974559.

6 A. D. James, J. P. Yomaira, T. Wang and H. S. Brent, US Pat., US 8642791 B2, 2014.

7 F. Salak Asghari and H. Yoshida, Ind. Eng. Chem. Res., 2006, 45, 2163-2173.
8 Z. Xue, M.-G. Ma, Z. Li and T. Mu, $R S C A d v .$, 2016, 6, 9887498892.

9 J. E. Romo, N. V. Bollar, C. J. Zimmermann and S. G. Wettstein, ChemCatChem, 2018, 10, 4819-4830.

10 G. Portillo Perez, A. Mukherjee and M.-J. Dumont, Insights into HMF catalysis, J. Ind. Eng. Chem., 2019, 70, 1-34.

11 M. Sajid, X. Zhao and D. Liu, Green Chem., 2018, 20, 54275453.

12 S. Dee and A. Bell, ChemSusChem, 2011, 4, 1166-1173.

13 B. F. M. Kuster, Starch/Staerke, 1990, 42, 314-321.

14 S. Hu, Z. Zhang, J. Song, Y. Zhou and B. Han, Green Chem., 2009, 11, 1746-1749.

15 Y. Shen, J. Sun, Y. Yi, M. Li, B. Wang, F. Xu and R. Sun, Bioresour. Technol., 2014, 172, 457-460.

16 L. Li, J. Ding, J.-G. Jiang, Z. Zhu and P. Wu, Chin. J. Catal., 2015, 36, 820-828.

17 J. Chheda and J. Dumesic, Green Chem., 2007, 9, 342-350.

18 J. Sun, X. Yuan, Y. Shen, Y. Yi, B. Wang, F. Xu and R. Sun, Ind. Crops Prod., 2015, 70, 266-271.

19 T. Zhang, W. Fan, W. Li, Z. Xu, H. Xin, M. Su, Y. Lu and L. Ma, Energy Technol., 2016, 5, 747-755.

20 V. Degirmenci and E. Hensen, Environ. Prog. Sustainable Energy, 2013, 33, 657-662.

21 R. M. Musau and R. M. Munavu, Biomass, 1987, 13, 67-74.

22 J. Zhao, C. Zhou, C. He, Y. Dai, X. Jia and Y. Yang, Catal. Today, 2016, 264, 123-130.

23 D. J. Tuteja, S. Nishimura and K. Ebitani, Bull. Chem. Soc. Jpn., 2012, 85, 275-281.

24 F. Su and Y. Guo, Green Chem., 2014, 16, 2934-2957.

25 X. Qi, M. Watanabe and T. Aida, Green Chem., 2008, 10, 799805.

26 J. Li, H. Zhao, X. Hou, W. Fa and J. Cai, Micro Nano Lett., 2016, 12, 53-57.

27 F. Huang, Y. Su, Y. Tao, W. Sun and W. Wang, Fuel, 2018, 226, 417-422.

28 H. Abou-Yousef and E. B. Hassan, Fuel, 2014, 137, 115-121.

29 C. Zhou, J. Zhao, A. E. Yagoub, H. Ma, X. Yu, H. Jiali, X. Bao and S. Liu, Egypt. J. Pet., 2017, 26, 477-487.

30 J. Horvat, B. Klaić, B. Metelko and V. Šunjić, Tetrahedron Lett., 1985, 26, 2111-2114.

31 D. Chen, F. Liang, D. Feng, M. Xian, H. Zhang, H. Liu and F. Du, Chem. Eng. J., 2016, 300, 177-184.

32 I. Elsayed, M. Mashaly, F. Eltaweel, M. A. Jackson and E. B. Hassan, Fuel, 2018, 221, 407-416.

33 Z. Zhang, B. Du, L.-J. Zhang, Y.-X. Da, Z.-J. Quan, L.-J. Yang and X.-C. Wang, RSC Adv., 2013, 3, 9201-9205.

34 M. L. Mednick, J. Org. Chem., 1962, 27, 398-403.

35 Z. Zhang, Q. Wang, H. Xie, W. Liu and Z. Zhao, ChemSusChem, 2011, 4, 131-138.

36 R. Thombal and V. Jadhav, Appl. Catal., A, 2015, 499, 213216.

37 I. Jiménez-Morales, M. Moreno-Recio, J. SantamaríaGonzález, P. Maireles-Torres and A. Jiménez-López, Appl. Catal., B, 2015, 164, 70-76. 